\title{
Loss of miR-638 promotes invasion and epithelial-mesenchymal transition by targeting SOX2 in hepatocellular carcinoma
}

\author{
YU ZHANG $^{1}$, DI ZHANG ${ }^{2}$, JIONG JIANG ${ }^{1}$ and LEI DONG ${ }^{1}$ \\ Departments of ${ }^{1}$ Gastroenterology, ${ }^{2}$ General Surgery, The Second Affiliated Hospital \\ of Xi'an Jiaotong University, Xi'an, Shaanxi 710004, P.R. China
}

Received June 27, 2016; Accepted November 16, 2016

DOI: 10.3892/or.2016.5273

\begin{abstract}
Aberrant expression of microRNAs has been identified as regulators of biological processes of hepatocellular carcinoma (HCC) by negatively regulating protein-coding mRNAs. Several studies have demonstrated that miR-638 expression was dysregulated in various human cancers. However, the clinical significance and underlying mechanisms of miR-638 involved in HCC remain to be elucidated. Herein, we confirmed that a reduced miR-638 expression was present in HCC tissues and cell lines. Our clinical analysis revealed that the downregulated miR-638 expression was significantly correlated with poor prognostic features including high Edmondson-Steiner grade, venous infiltration and advanced tumor-node-metastasis (TNM) stage. Moreover, we demonstrated that miR-638 was a novel independent prognostic marker for predicting 5-year survival of HCC patients. Functionally, overexpressed miR-638 expression inhibited cell migration and invasion, while downregulated miR-638 reversed the effect. In addition, miR-638 could regulate SOX 2 by directly binding to its 3 '-UTR. Alternation of SOX2 expression at least partially abolished the migration and invasion effects of miR-638 on HCC cells. Aberrant miR-638 expression could regulate the expression level of epithelial-to-mesenchymal transition markers in vitro and in vivo by modulating SOX2 expression. In conclusion, our data indicated that miR-638 functioned as a tumor suppressor gene and play a critical role in the development of HCC.
\end{abstract}

\section{Introduction}

MicroRNAs (miRNAs) are an endogenous group of small non-coding single-stranded RNAs that play critical roles in different biological processes through negatively regulating

Correspondence to: Professor Lei Dong, Department of Gastroenterology, The Second Affiliated Hospital of Xi'an Jiaotong University, 157 Xiwu Road, Xi'an, Shaanxi 710004, P.R. China E-mail: dl4488@sina.com

Key words: microRNA-638, hepatocellular carcinoma, SOX2, epithelial to mesenchynal transition, invasion various genes at posttranscriptional level, predominantly by interacting with the 3'-untranslated regions (3'UTR) by targeting corresponding messenger RNAs (mRNAs) $(1,2)$. Increasing evidence has demonstrated that aberrant miRNAs are implicated in cellular processes, including cell cycle, differentiation, proliferation, apoptosis and tumorigenesis (3). Previous studies have identified the pivotal role in human tumors and indicate that abnormal miRNAs are involved in the initiation, progression, migration and invasion of human cancers by modulating the target mRNAs expression of oncogenes or suppressor genes, including hepatocellular carcinoma (HCC) $(4,5)$. Hence, miRNAs have been regarded as a novel promising indicator and attractive therapeutic strategy for HCC patients.

Recently, mounting studies demonstrated that miR-638 function as a critical regulator of tumorigenesis, development and progression. miR-638 played an important role in a wide range of human cancers (6-10). For instance, miR-638 functions as suppressor to inhibit cell proliferation, invasion and regulate cell cycle by targeting tetraspanin 1 in human colorectal carcinoma (CRC) and a low expression of miR-638 is associated with poor survival prognosis of CRC patients (11). miR-638 suppresses gastric cancer cell proliferation by targeting specificity protein 2 (Sp2) with influence on the expression of cyclin D1 (12). However, miR-638 supports melanoma metastasis and progression and suppresses p53-mediated apoptosis pathways and autophagy by targeting the TP53INP2 transcription (13). miR-638 is overexpressed in human vascular smooth muscle cells and inhibits PDGFBB-induced cell proliferation and migration through targeting orphan nuclear receptor NOR1 (14). Therefore, the functional significance of miR-638 in cancer progression seem to be cancer-type specific. Recently, miR-638 was reported to be downregulated in HCC specimens and to inhibit angiogenesis and growth of HCC by targeting VEGF (15). However, the clinical significance of miR-638 and the underlying mechanisms implicated in the initiation and development of HCC remain to be investigated.

Epithelial to mesenchymal transition (EMT) has been proposed to have a critical role in the invasion and metastasis of different cancers through transformation of adherent and polarized epithelial cells interacting with the basement membrane by its basal surface, into invasive and motile mesenchymal cells $(16,17)$. It is characterized by loss of epithelial traits, such as 
E-cadherin repression, accompanied by gain of mesenchymal features, such as increased N-cadherin and vimentin (18). Accumulated evidence revealed that EMT plays an important role in HCC invasion and metastasis. Recent studies have demonstrated that miRNAs are involved in the EMT process in HCC development $(8,19)$. However, the association between miR-638 and EMT in HCC has remained elusive.

In this study, we investigated the critical role of miR-638 in HCC progression. Our results revealed that miR-638 was downregulated in the $\mathrm{HCC}$ and the reduced miR-638 was associated with adverse prognostic characteristics and poor 5-year survival of HCC patients. We identified that miR-638 could regulate the migration and invasion of $\mathrm{HCC}$ by targeting SOX2 in vitro. Furthermore, miR-638 induced EMT phenotype in vitro and in vivo. These data identify the underlying mechanism by which miR-638 inhibits migration and invasion of HCC, and miR-638 is regarded as a novel prognostic biomarker for HCC patients.

\section{Materials and methods}

Clinical tissues and cell cultures. The HCC samples and matched adjacent tissues from 113 patients who underwent radical surgical resection at the Second Affiliated Hospital of Xi'an Jiaotong University from March 2007 to June 2009 were studied. Tissues were immediately snap-frozen and stored at $-80^{\circ} \mathrm{C}$ for RNA extraction. None of the patients had received any perioperative chemo- or radiotherapy. The patients signed an informed consent form, and this research was approved by the Ethics Committee of Xi'an Jiaotong University.

The human HCC cell lines Hep3B, HepG2, MHCC-97L, SMMC-7721, MHCC-97H and the normal human immortalized hepatocyte LO2 cells were obtained from the Institute of Biochemistry and Cell Biology (Chinese Academy of Sciences, Shanghai, China) and were cultured in Dulbecco's modified Eagle's medium (DMEM, Hyclone, Logan, UT, USA) containing 10\% FBS (Invitrogen, Carlsbad, CA, USA), $1 \%$ penicillin-streptomycin (Sigma, St. Louis, MO, USA). All the cells were incubated in a humidified atmosphere at $37^{\circ} \mathrm{C}$ with $5 \% \mathrm{CO}_{2}$.

RNA extraction and quantitative real-time polymerase chain reaction ( $q R T-P C R$ ). Total RNA from HCC tissues and cells was extracted using TRIzol reagent (Invitrogen) according to the manufacturer's protocol. cDNA was reverse-transcribed from $1 \mu \mathrm{g}$ total RNA using a Reverse Transcription kit (Takara Biochemicals, Tokyo, Japan). cDNA was then amplified with a SYBR ${ }^{\circledR}$ Premix Ex Taq ${ }^{\mathrm{TM}}$ II (Perfect Real-Time) kit (Takara Biochemicals). The gene expression levels were calculated using the $\Delta \Delta \mathrm{Ct}$ method with U6 or GAPDH as an internal control. Hsa-miR-638 primer (HmiRQP0748), snRNA U6 qPCR Primer (HmiRQP9001), SOX2 (HQP017628) and GAPDH (HQP006940) were purchased from Genecopoeia (Guangzhou, China).

Western blotting. The whole proteins from cultured cells and tissues was quantified with BCA Protein Assay kit (Thermo Scientific, Rockford, IL, USA), and an equal amount of $40 \mu \mathrm{g}$ protein was separated by $10 \%$ SDS-PAGE and then transferred onto PVDF membranes (Millipore, Billerica, MA, USA). The
Table I. The relationship between miR-638 expression and clinicopathological feature in HCC $(n=113)$.

\begin{tabular}{|c|c|c|c|c|}
\hline \multirow[b]{2}{*}{ Clinical parameters } & \multirow[b]{2}{*}{$\begin{array}{l}\text { Cases } \\
\text { (n) }\end{array}$} & \multicolumn{2}{|c|}{ Expression level } & \multirow[b]{2}{*}{ P-value } \\
\hline & & $\begin{array}{c}\mathrm{miR}-638^{\text {high }} \\
\quad(\mathrm{n}=54)\end{array}$ & $\begin{array}{c}\mathrm{miR}-638^{\text {low }} \\
\quad(\mathrm{n}=59)\end{array}$ & \\
\hline \multicolumn{5}{|l|}{ Age (years) } \\
\hline$<60$ years & 35 & 16 & 19 & 0.768 \\
\hline$\geq 60$ years & 78 & 38 & 40 & \\
\hline \multicolumn{5}{|l|}{ Gender } \\
\hline Male & 89 & 44 & 45 & 0.499 \\
\hline Female & 24 & 10 & 14 & \\
\hline \multicolumn{5}{|l|}{ Tumor size $(\mathrm{cm})$} \\
\hline$<5 \mathrm{~cm}$ & 67 & 32 & 35 & 0.995 \\
\hline$\geq 5 \mathrm{~cm}$ & 46 & 22 & 24 & \\
\hline \multicolumn{5}{|l|}{ Tumor number } \\
\hline Solitary & 99 & 49 & 50 & 0.334 \\
\hline Multiple & 14 & 5 & 9 & \\
\hline \multicolumn{5}{|l|}{ Edmondson } \\
\hline $\mathrm{I}+\mathrm{II}$ & 42 & 28 & 14 & $0.002^{\mathrm{a}}$ \\
\hline III+IV & 71 & 26 & 45 & \\
\hline \multicolumn{5}{|l|}{ TNM stage } \\
\hline $\mathrm{I}+\mathrm{II}$ & 96 & 51 & 45 & $0.007^{\mathrm{a}}$ \\
\hline III+IV & 17 & 3 & 14 & \\
\hline \multicolumn{5}{|l|}{ Venous infiltration } \\
\hline Present & 15 & 2 & 13 & $0.004^{\mathrm{a}}$ \\
\hline Absent & 98 & 52 & 46 & \\
\hline \multicolumn{5}{|l|}{ AFP } \\
\hline$<400 \mathrm{ng} / \mathrm{ml}$ & 30 & 15 & 15 & 0.777 \\
\hline$\geq 400 \mathrm{ng} / \mathrm{ml}$ & 83 & 39 & 44 & \\
\hline \multicolumn{5}{|l|}{ HBsAg } \\
\hline Positive & 101 & 49 & 52 & 0.653 \\
\hline Negative & 12 & 5 & 7 & \\
\hline
\end{tabular}

${ }^{\mathrm{a}} \mathrm{p}<0.05$.

membranes were blocked with 5\% nonfat milk in TBST for $2 \mathrm{~h}$ at room temperature and incubated overnight with respective primary antibodies (1:1000, Cell Signaling Technology, Inc.) at $4^{\circ} \mathrm{C}$. Then the membranes were washed three times by TBST and incubated with appropriate HRP-conjugated secondary antibody for $2 \mathrm{~h}$ at room temperature (ZSGB-BIO, Beijing, China). Detection was performed by enhanced chemiluminescence kit (Amersham, Little Chalfont, UK).

Cell transfection. Hsa-miR-638 precursor was purchased from Songon Tech (Beijing, China) and inserted into pcDNA6.2GW/EmGFPmiR vector (named miR-638) according to the manufacturer's instructions. miR-638 inhibitor (HmiRAN0748) and the negative control (CmiR-AN0001-AM04) were obtained from Genecopoeia. The SOX2 overexpression 

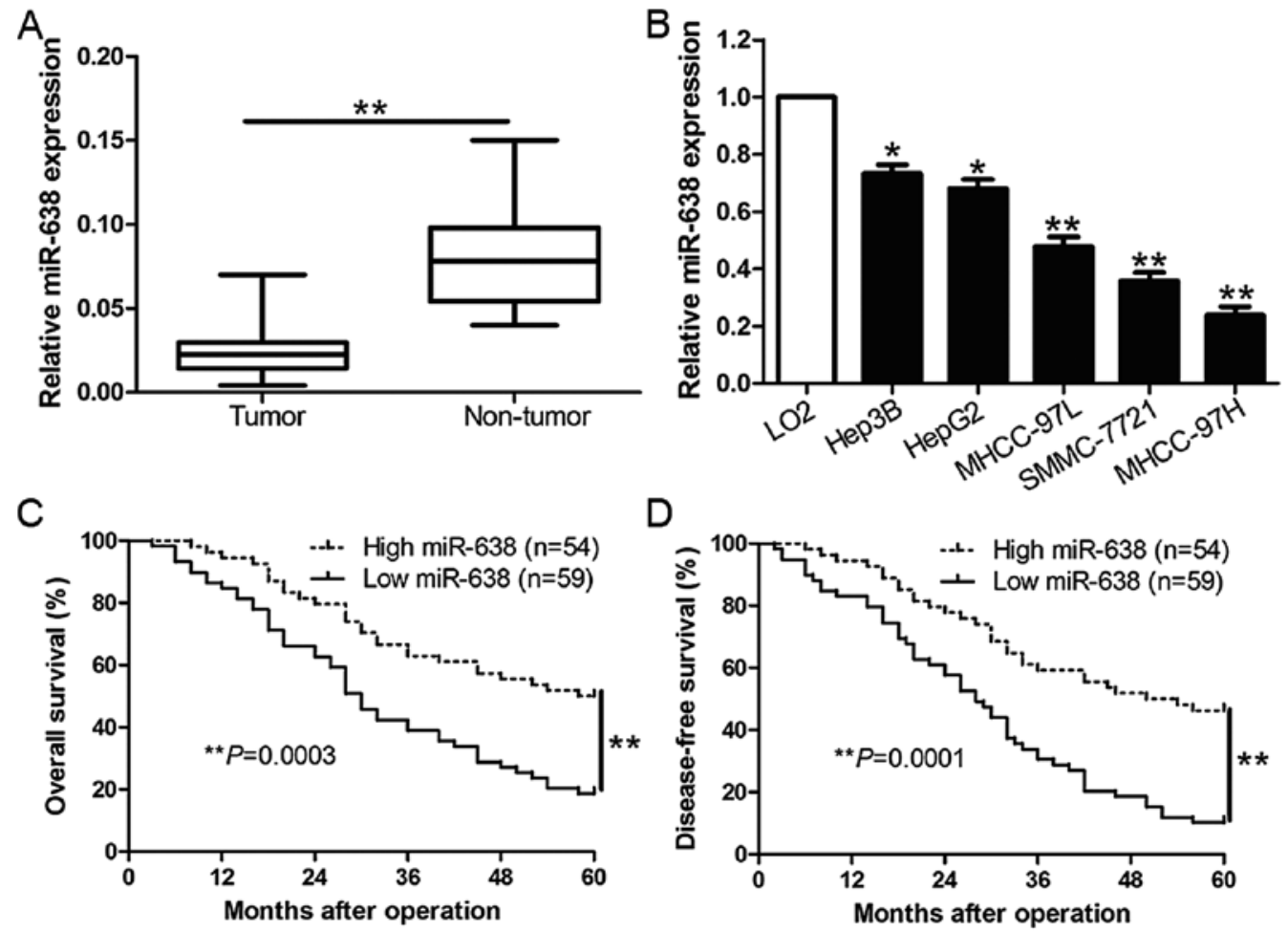

Figure 1. Clinical significance of reduced miR-638 in HCC samples. (A) Quantification of the data revealed that the mean level of miR-638 expression in HCC tissues was significantly lower than that in matched adjacent non-tumor tissues. (B) Comparing differences in the expression levels of miR-638 between HCC cell lines compared to the immortalized hepatic cell line LO2. $n=6$ repeats with similar results. U6 snRNA was used as internal control. HCC patients with higher expression of miR-638 had better (C) overall survival and (D) disease-free survival ${ }^{*} \mathrm{P}<0.05,{ }^{* *} \mathrm{P}<0.01$.

plasmid and specific siRNA against SOX2 (sense, 5'-GGA AUGGACCUUGUAUAGAUC-3'; anti-sense, 5'-UCUAUAC AAGGUCCAUUCCCC-3') and a scramble siRNA were synthesized by Sangon Biotech Co., Ltd. (Shanghai, China). Cells were transfected with the above vectors using Lipofectamine 2000 Reagent (Invitrogen Life Technologies) in accordance with the manufacturer's protocol.

Immunohistochemical staining. Immunohistochemical staining was performed on $4 \mu \mathrm{m}$ sections of paraffin-embedded tissues to detect the protein expression. The corresponding antibody (1:300, Cell Signaling Technology, Inc.) was applied as the primary antibody by a streptavidin peroxidase-conjugated (SP-IHC) method. The staining results were semi-quantitatively evaluated by the multiplicity of staining intensity and the percentage of positive staining cells. The percentage of positive cells was graded: 0 for $<5 \%$; 1 for $6-25 \%$; 2 for $26-50 \%$; 3 for $51-75 \%$ and 4 for $>75 \%$. Staining intensity was assessed by four degrees: 0, negative; 1, weak; 2, moderate; and 3, strong. Each section was assayed in ten independent high magnification (x400) fields to obtain the average scores.

Cell migration and invasion assays. Matrigel-uncoated and coated Transwell inserts ( $8 \mu \mathrm{m}$ pore size; Millipore) were used to evaluate cell migration and invasion. Briefly, $5 \times 10^{4}$ transfected cells were suspended in $200 \mu \mathrm{l}$ serum free DMEM medium in the upper chamber, and $750 \mu 1$ DMEM medium containing $10 \%$ FBS was placed in the lower chamber. After $24 \mathrm{~h}$ of incubation, cells were fixed in $4 \%$ paraformaldehyde for $20 \mathrm{~min}$ and stained with $0.1 \%$ crystal violet dye for $15 \mathrm{~min}$.
The cells on the inner layer were softly removed with a cotton swab and counted at five randomly selected views, and the average cell number per view was calculated.

Dual-luciferasee reporter gene assay. The 3'-UTR sequence of SOX2 was predicted to interact with miR-638, together with a corresponding mutated sequence within the predicted target sites, were synthesized and inserted into the pRL-TK control vector (Promega, Madison, WI, USA) called wt-SOX2 3'-UTR and mt-SOX2 3'-UTR. Subsequently, MHCC-97H cells that were plated into a 24-well plate and were transfected with $120 \mathrm{ng}$ miR-638 inhibitor or negative control. Cells were co-transfected with $30 \mathrm{ng}$ of the wild-type or mutant 3'-UTR of SOX2 vector using Lipofectamine 2000 reagent (Invitrogen). After $48 \mathrm{~h}$, cells were harvested and measured according to the manufacturer's instructions (Dual-Luciferase Assay System; Promega). pRL-TK expressing Renilla luciferase was co-transfected as an internal control to correct the differences in both transfection and harvest efficiencies.

In vivo metastasis assay. Female BALB/c nude mice (4-6 weekold) (Centre of Laboratory Animals, The Medical College of Xi'an Jiaotong University, Xi'an, China) were randomized into two groups $(n=5)$, and either MHCC-97H-miR-638 or MHCC-97H-miR-control cells $\left(1 \times 10^{6}\right)$ were injected into the tail veins for the establishment of a pulmonary metastatic model. Mice were sacrificed 10 weeks post-injection and examined microscopically by H\&E staining for the development of lung metastatic foci. Animals were housed in cages under standard conditions. All in vivo protocols were approved 


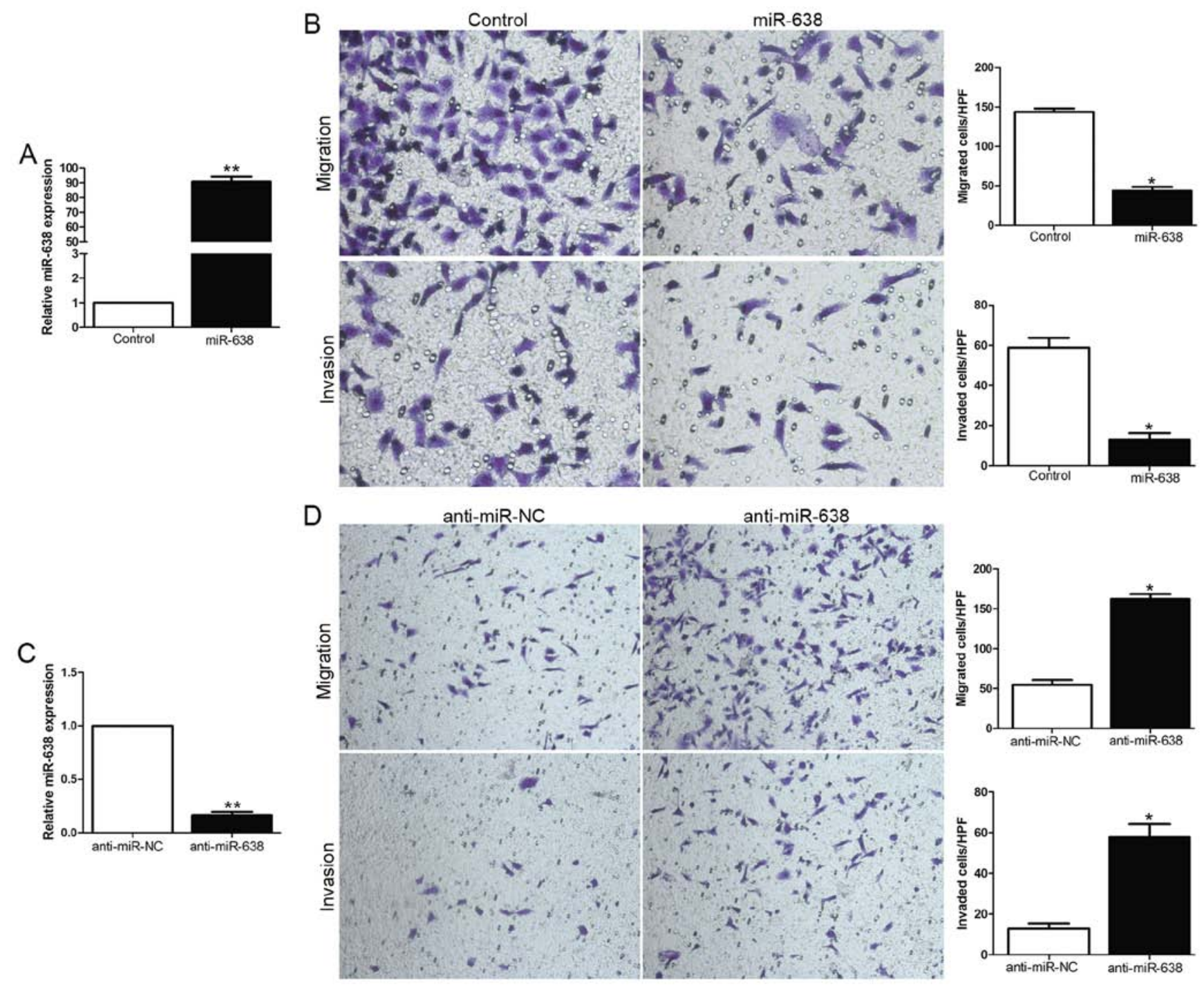

Figure 2. miR-638 inhibits HCC cell migration and invasion in vitro. (A) MHCC-97H cells that were transfected with corresponding miRNA vectors were subjected to qRT-PCR for miR-638. (B) Cell migration and invasion as measured by Transwell assays were inhibited by overexpression of miR-638 in MHCC-97H cells. (C) Hep3B cells that were transfected with miR-638 inhibitors (anti-miR-638) and negative control were subjected to qRT-PCR for miR-638. (D) Cell migration and invasion as measured by Transwell assays were increased by knockdown of miR-638 in Hep3B cells. $\mathrm{n}=6$ independent experiments ${ }^{*} \mathrm{P}<0.05,{ }^{* *} \mathrm{P}<0.01$.

by the Institutional Animal Care and Use Committee of Xi'an Jiaotong University.

Statistical analysis. Data are presented as the mean \pm SD and performed at least three independent replicates. SPSS software, 16.0 (SPSS, Inc, Chicago, IL, USA) and Graphpad Prism 6.0 (GraphPad Software, Inc., La Jolla, CA, USA) were used for a two-tailed Student's t-test, Pearson's correlation analysis, Kaplan-Meier method and the log-rank test to evaluate the statistical significance. Differences were defined as $\mathrm{P}<0.05$.

\section{Results}

Clinical significance of reduced miR-638 in HCC samples. To assess the expression level of miR-638 in HCC, we performed qRT-PCR to determine the expression of miR-638 in 113 pairs of HCC tissues and matched adjacent non-tumor tissues. As shown in Fig. 1A, the mean level of miR-638 expression in HCC tissues was obviously downregulated when compared to the matched non-tumor tissues $(\mathrm{P}<0.01$, Fig. $1 \mathrm{~A})$. Moreover, similar result was found in HCC cell lines. The data revealed that miR-638 was remarkably reduced in a panel of HCC cell lines than the normal hepatocyte cell line LO2 $(\mathrm{P}<0.05$, Fig. 1B). To further evaluate the role of miR-638 in the progression of HCC, we analyzed the relationship between miR-638 expression and the clinical characteristics and prognosis of HCC patients. With the median level of miR-638 as the cut-off, the low expression of miR-638 was prominently associated with high Edmondson-Steiner grading $(\mathrm{P}=0.002)$, venous infiltration $(\mathrm{P}=0.004)$ and tumor-node-metastasis (TNM) stage $(\mathrm{P}=0.007)$ (Table I). Furthermore, the low expression of miR-638 was closely correlated with poor overall survival (OS) $(\mathrm{P}=0.0003$, Fig. 1C) and disease-free survival (DFS) $(\mathrm{P}=0.0001$, Fig. 1D) in HCC patients. In addition, miR-638 expression was an independent factor for predicting both 5-year OS and DFS of HCC patients $(\mathrm{P}=0.016$ and 0.010 , respectively, Table II). Taken together, these data demonstrate that miR-638 showed reduced expression in HCC and inversely associated 


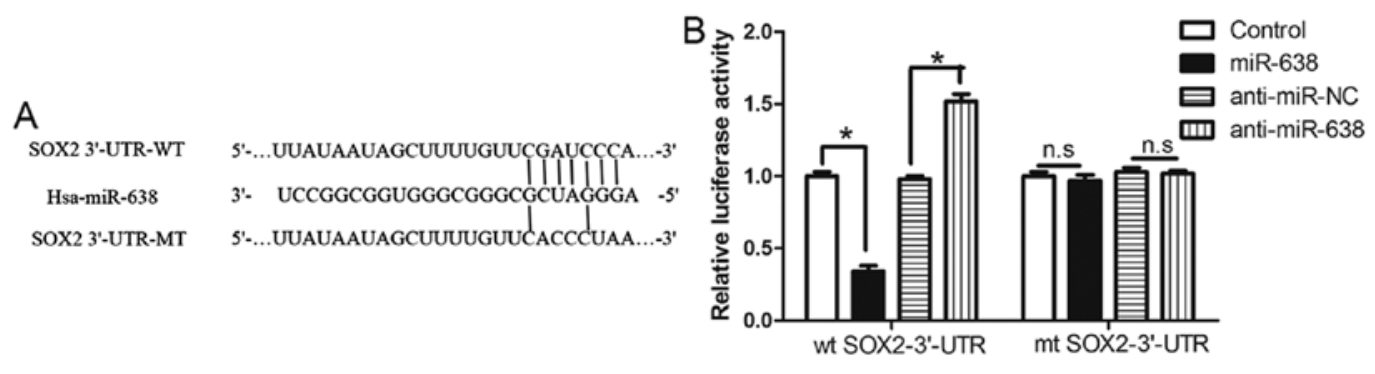

C
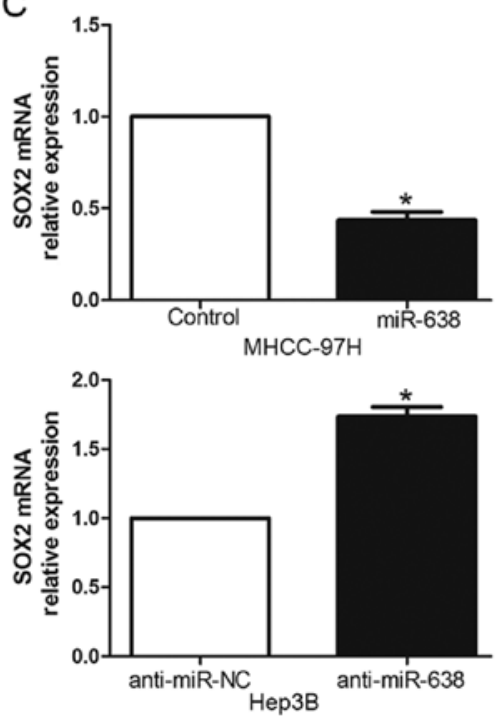

D
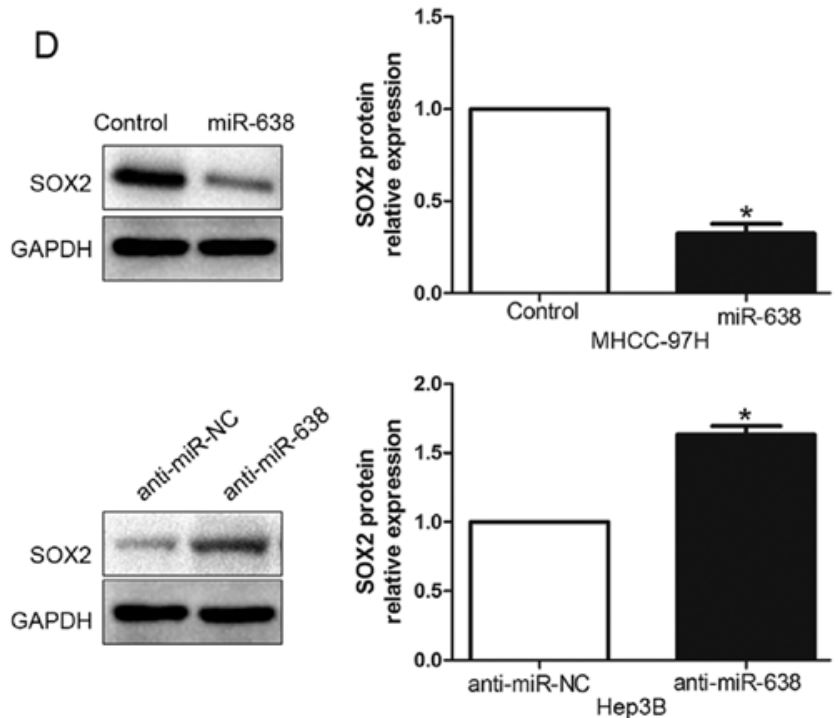

Figure 3. SOX2 is a direct target of miR-638 in HCC. (A) miR-638 and its putative binding sequence in the 3'-UTR of SOX2. The mutant binding site was generated in the complementary site for the seed region of miR-638. (B) miR-638 significantly suppresses the luciferase activity that carried wild-type (wt) but not mutant (mt) 3'-UTR of SOX2. Anti-miR-638 led to a notable increase in the luciferase activity of wt 3'-UTR of SOX2. (C) qRT-PCR analysis of SOX2 mRNA expression in MHCC-97H cells with miR-638 or miR-control vector transfection and Hep3B cells with anti-miR-638 or anti-miR-NC vector transfection. (D) Overexpression of miR-638 reduced the expression of SOX2 protein in MHCC-97H cells and knockdown of miR-638 increases the level of SOX2 protein in Hep3B cells. $\mathrm{n}=6$ repeats with similar results, ${ }^{*} \mathrm{P}<0.05$.

with clinical characters and prognosis of HCC patients, which suggest miR-638 was involved in the development of HCC.

miR-638 represses migration and invasion of HCC cells in vitro. We focused on the functional effects of miR-638 in HCC cells, gain- and loss-of-function assays were performed through transfection of miR-638 or anti-miR-638 expression vector into $\mathrm{HCC}$ cell lines with moderate miR-638 expression level. The transfection efficiency was confirmed by using qRT-PCR (Fig. 2A and C). As measured by Matrigel-coated (for invasion) and -uncoated (for migration) Transwell assays, ectopic expression of miR-638 significantly inhibited the migration and invasion of MHCC-97H cells ( $\mathrm{P}<0.05$, Fig. 2B), whereas the silencing of miR-638 expression obviously enhanced the number of migrated and invaded Hep3B cells $(\mathrm{P}<0.05$, Fig. 2D). In conclusion, these data suggested that miR-638 could inhibit HCC cell migration and invasion.

miR-638 directly inhibits SOX2 expression by interacting with its 3'-UTR. To elucidate the underlying mechanism of miR638-mediated suppression of cell migration and invasion, we used TargetScan and miRanda algorithms to search for putative protein-coding gene targets of miR-638. Bioinformatics software indicated that SOX2 3'-UTR binds to miR-638 with high score (Fig. 3A). Moreover, previous studies have confirmed that miR- 638 could modulate SOX 2 expression by directly binding its 3 '-UTR $(8,19)$. To verify this, we generated a luciferase reporter plasmid which carried the mutated binding site of miR-638 in the SOX2 3'-UTR and found that miR-638 overexpression significantly inhibited the luciferase activity of SOX2 containing a wild-type (wt) 3'-UTR but did not suppress the activity of SOX2 with a mutant (mt) 3'-UTR $(\mathrm{P}<0.05$, Fig. 3B). On the contrary, miR-638 suppression increased the luciferase activity of wt SOX2 3'-UTR $(\mathrm{P}<0.05$, Fig. 3B) but had no effect on mt SOX2 3'-UTR constructs. Subsequently, we examined the response to the alteration of miR-638 expression in vitro. Our data showed the negative regulatory effect of miR-638 on SOX2 both in MHCC-97H and Hep3B cell lines. Overexpression of miR-638 inhibited SOX2 expression, moreover, downregulated miR-638 could increase SOX2 expression both in mRNA ( $\mathrm{P}<0.05$, Fig. 3C) and protein $(\mathrm{P}<0.05$, Fig. 3D) level. These data indicated that miR-638 could modulate SOX 2 expression by directly binding its 3 '-UTR in HCC cells.

SOX2 levels are negatively correlated with miR-638 expression. To further evaluate the relationship between SOX2 and miR-638 in HCC tissues, we investigated the SOX2 mRNA and protein expression in different miR-638 levels. As expected, we demonstrated that both SOX2 mRNA and protein expression level in high miR-638 group were significantly lower compared with those in low miR-638 group in $\mathrm{HCC}(\mathrm{P}<0.05$, 


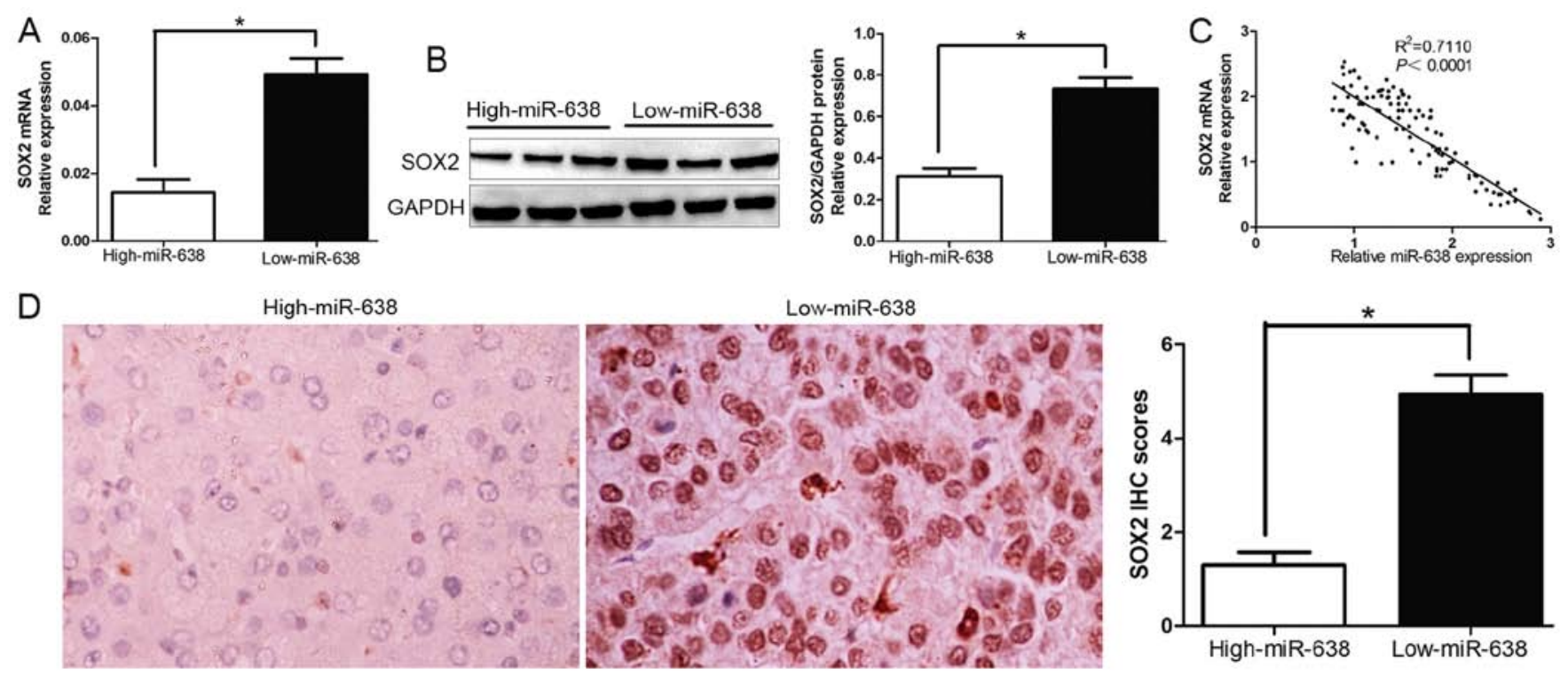

Figure 4. An inverse correlation between miR-638 and SOX2 expression is observed in 113 HCC samples. (A) The expression of SOX2 mRNA in miR-638 high-expressing tumors was significantly lower than that in miR-638 low-expressing tumors. (B) The expression of SOX2 protein in miR-638 high-expressing tumors was significantly lower than that in miR-638 low-expressing tumors. (C) A significant inverse correlation between the mRNA levels of SOX2 and miR-638 was observed in HCC tissues. (D) Representative immunohistochemical staining showed a weak staining of SOX2 in miR-638 high-expressing HCC tissue and strong staining of SOX 2 in the miR-638 low-expressing tumor. $\mathrm{n}=6$ repeats with similar results. ${ }^{*} \mathrm{P}<0.05$.

Table II. Multivariate Cox regression analysis of 5-year OS and DFS of 113 HCC patients.

\begin{tabular}{|c|c|c|c|c|c|c|}
\hline \multirow[b]{2}{*}{ Variables } & \multicolumn{3}{|c|}{ Overall survival } & \multicolumn{3}{|c|}{ Disease-free survival } \\
\hline & HR & $95 \% \mathrm{CI}$ & P-value & HR & $95 \% \mathrm{CI}$ & P-value \\
\hline miR-638 expression & 0.254 & $0.076-0.812$ & $0.016^{\mathrm{a}}$ & 0.238 & $0.072-0.667$ & $0.010^{\mathrm{a}}$ \\
\hline Edmondson grade & 1.196 & $0.679-3.385$ & 0.219 & 1.106 & $0.658-1.069$ & 0.284 \\
\hline TNM stage & 2.475 & $1.342-5.917$ & $0.006^{\mathrm{a}}$ & 2.217 & $1.128-4.864$ & $0.008^{\mathrm{a}}$ \\
\hline Venous infiltration & 2.894 & $1.776-6.049$ & $0.003^{\mathrm{a}}$ & 3.012 & $1.893-6.347$ & $0.001^{\mathrm{a}}$ \\
\hline
\end{tabular}

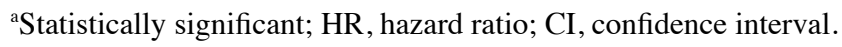

Fig. 4A and B). Furthermore, the results showed that the mRNA level of SOX2 in the HCC tissues was inversely correlated with miR-638 expression $\left(\mathrm{R}^{2}=0.711, \mathrm{P}<0.0001\right.$, Fig. $\left.4 \mathrm{C}\right)$. Consistently, as assessed by IHC assay, SOX2 protein expression in miR-638 high-expressing tumors was obviously lower than miR-638 low-expressing tumors $(\mathrm{P}<0.05$, Fig. $4 \mathrm{D})$, which was similar with previous studies. The data suggested that the increased SOX2 expression in HCC was caused by miR-638 downregulation. Taken together, these results indicated that SOX2 was a target gene of miR-638 in HCC.

Alterations of SOX 2 expression levels influences the effects of miR-638 on HCC cells. To further determine that SOX2 is a functional target of miR-638, we overexpressed SOX2 by the transfecting SOX2 expression plasmid in MHCC97H-miR-638 cells, or silenced SOX2 by SOX2 siRNA in Hep3B-anti-miR-638 cells $(\mathrm{P}<0.05$, Fig. $5 \mathrm{~A}$ and $\mathrm{C})$. As expected, restoration of SOX2 expression partially abrogated the migration and invasion suppressive effect of miR-638 on MHCC-97H cells ( $\mathrm{P}<0.05$, Fig. 5B). Additionally, SOX2
siRNA reversed the effects of miR-638 inhibition on Hep3B cells $(\mathrm{P}<0.05$, Fig. 5D). Taken together, these experimental data suggest that the migration and invasion effect of HCC are regulated by miR-638, and these miR-638 functions at least partially rely on the suppression of SOX2 expression.

Loss of miR-638 promotes a mesenchymal-like transition in HCC cells. EMT has been identified as a pivotal role in the invasion of diverse cancer cells by the transformation of polarized and adherent epithelial cells into invasive mesenchymal cells. To confirm whether miR-638 was implicated in the EMT process, we examined the epithelial marker (E-cadherin) and mesenchymal marker (N-cadherin and vimentin) through western blotting. We found upregulated miR-638 increased the epithelial marker E-cadherin and decreased $\mathrm{N}$-cadherin and vimentin expression ( $\mathrm{P}<0.05$, Fig. $6 \mathrm{~A})$. In contrast, inhibition of miR-638 suppressed $\mathrm{E}$-cadherin expression and induced $\mathrm{N}$-cadherin and vimentin expression ( $\mathrm{P}<0.05$, Fig. 6B). Furthermore, we determined the correlation between miR-638 expression and E-cadherin expression and vimentin expression in HCC tissues. 
A
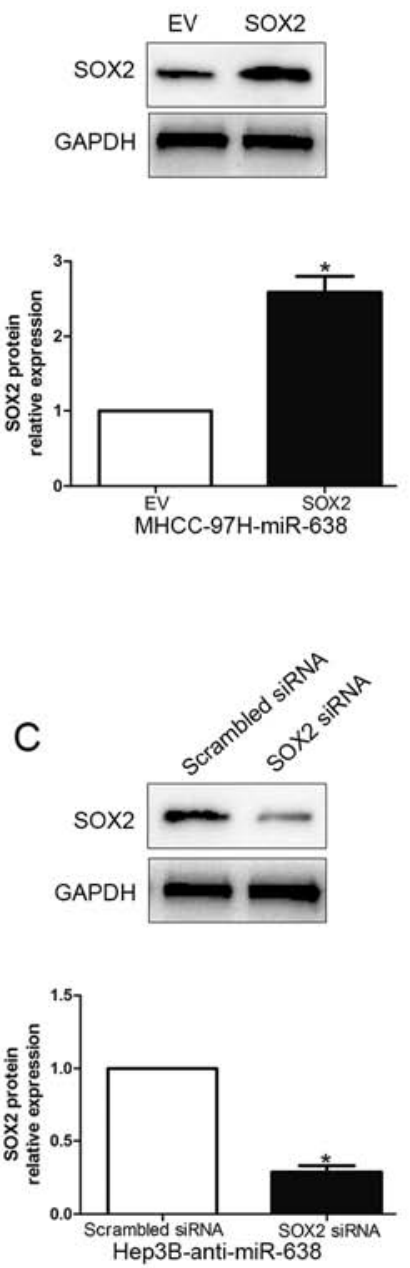

B
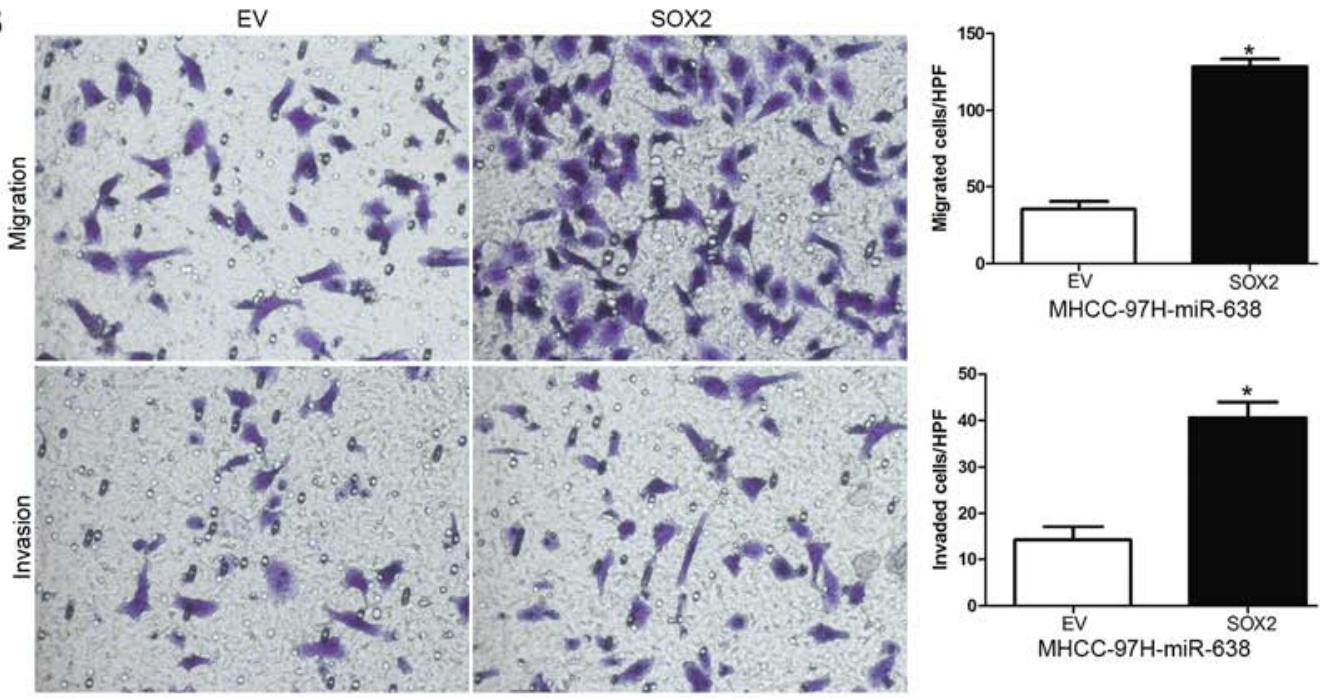

D

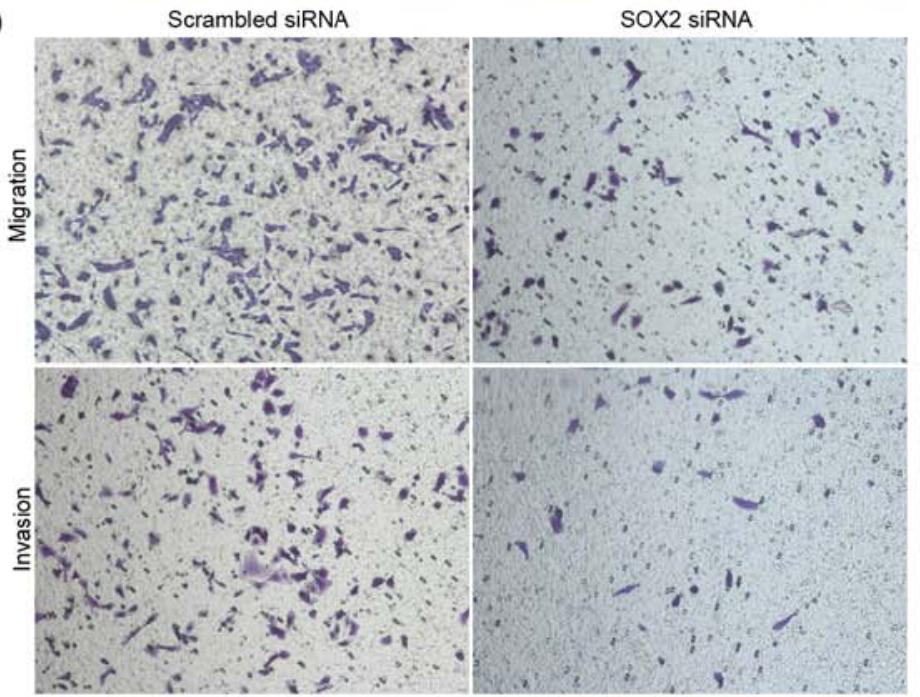

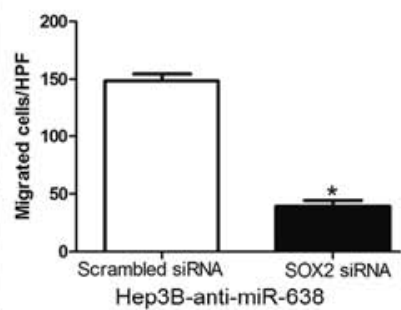

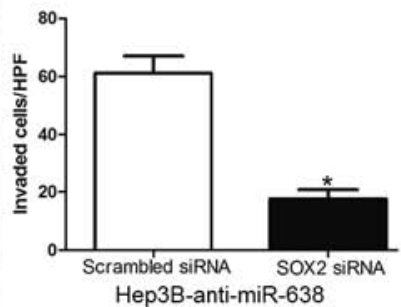

Figure 5. Alterations of SOX2 partially abolish miR-638-mediated HCC cell migration and invasion. (A) miR-638-overexpressing MHCC-97H cells that were transfected with EV or SOX2 expression plasmid were subjected to western blot analysis for SOX2. (B) Cell migration and invasion of the miR638-overexpressing MHCC-97H cells was increased by SOX2 overexpression. (C) miR-638-suppressive Hep3B cells that were transfected with scrambled siRNA or SOX2 siRNA were subjected to western blot analysis for SOX2. (D) SOX2 knockdown abrogated the effects of miR-638 knockdown on HCC cells. $\mathrm{n}=6$ independent experiments. $\mathrm{EV}$, empty vector. ${ }^{*} \mathrm{P}<0.05$.

We found that the E-cadherin expression in high miR-638 group was higher than that in low miR-638 group. Conversely, the expression level of vimentin in the high miR-638 group was significantly lower than that in low miR-638 group $(\mathrm{P}<0.05$, Fig. 6C). Taken together, these data indicated that miR-638 might contribute to regulation of EMT in HCC.

miR-638 mediated repression of SOX2 ameliorates the metastatic potential of HCC cells in vivo. To further verify the molecular mechanism and biological function of miR-638, we subsequently injected MHCC-97H-miR-638 and MHCC$97 \mathrm{H}$-control cells into the lateral veins of the nude mice. We found that miR-638 overexpression showed fewer and smaller foci in the lungs of the nude mice after injection through microscopic evaluation (8 vs. 24 nodules per lung in MHCC97H-miR-638 and miR-control cells, respectively; $\mathrm{P}<0.01$, Fig. 7A). Moreover, we also demonstrated that lung sections of overexpressed miR-638 in fact showed decreased SOX2 and vimentin expression and conversely increased E-cadherin expression (Fig. 7B). Collectively, these results indicated that miR-638 is capable of manipulating invasive biological function and EMT phenotype of HCC by targeting SOX2 both in vitro and in vivo.

\section{Discussion}

HCC is one of the most frequent malignancies and the third leading cause of cancer-related death worldwide $(20,21)$. Recent investigations demonstrated that miRNAs played a pivotal regulatory role in cancer initiation, proliferation, migration, invasion and other various cellular processes. Therefore, miRNAs are increasingly identified as a promising and potential diagnostic and therapeutic target of HCC. In previous studies, Manfred et al showed that the overexpression of miR-638 promoted the proliferation, migration and colony formation properties of melanoma cells both in vitro and metastatic capacities in vivo. miR-638 has an oncogenic role in protecting melanoma cells from apoptosis and autophagy. 
A

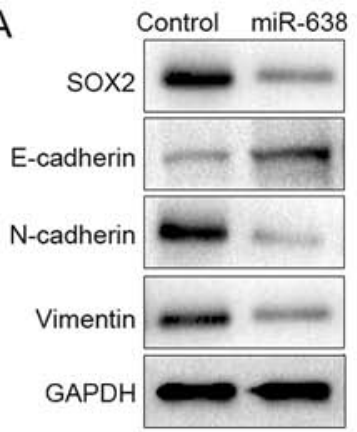

C
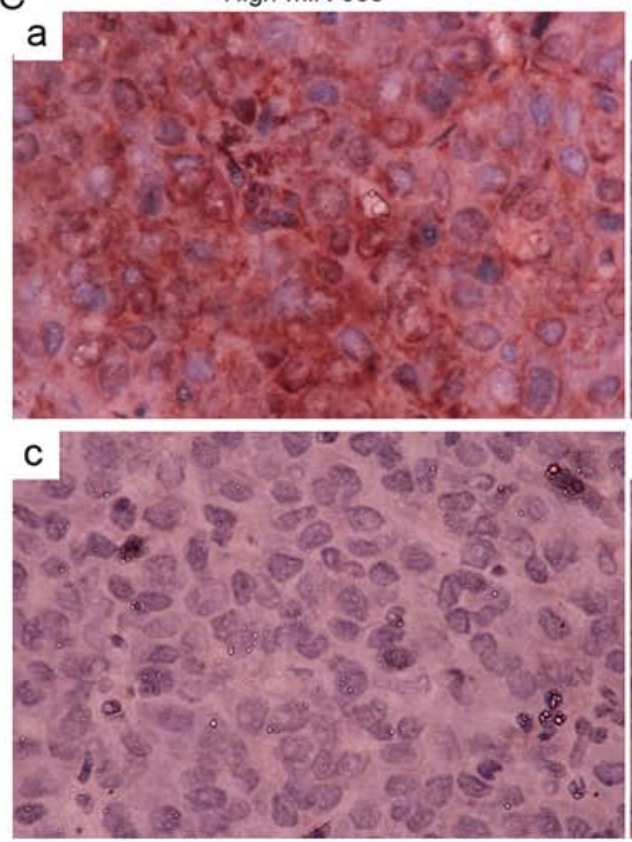

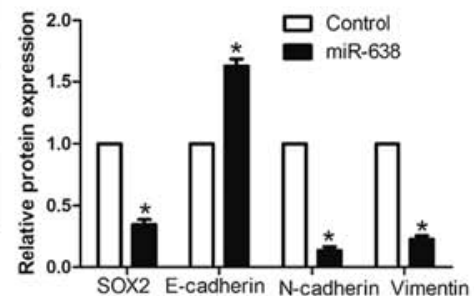

B

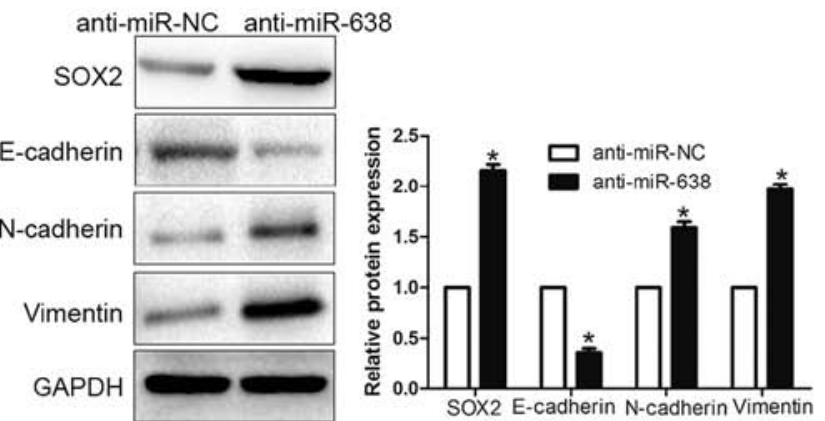

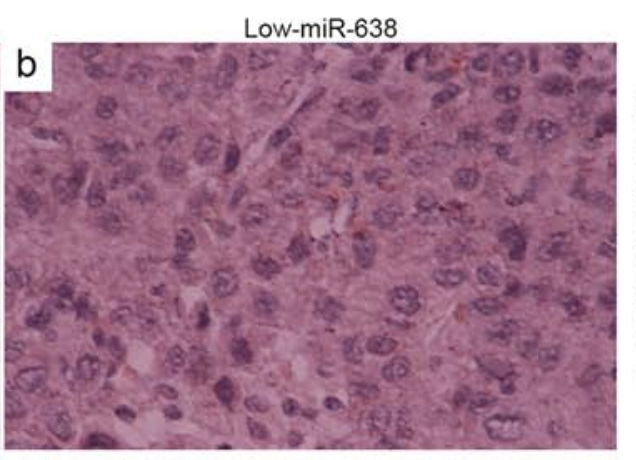

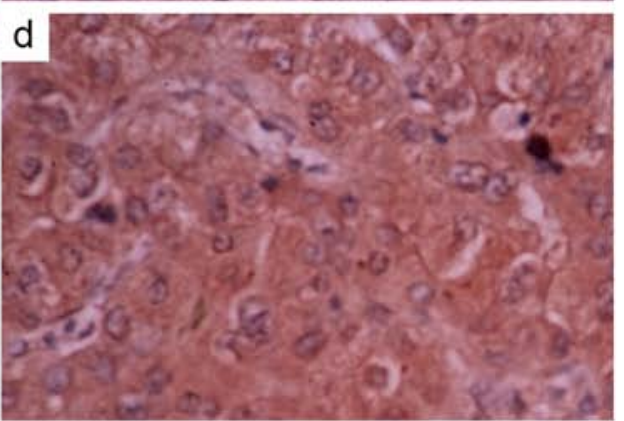

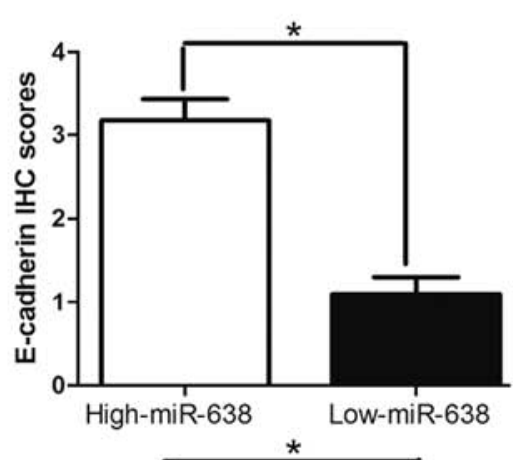

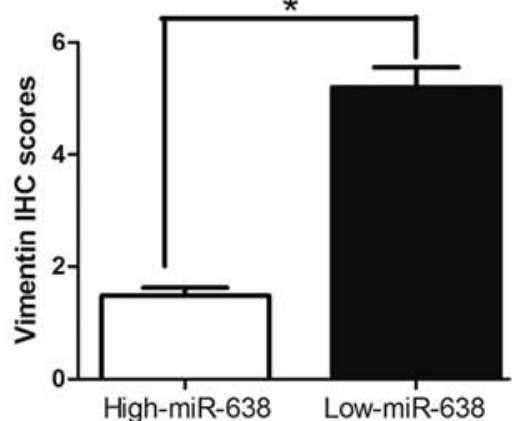

Figure 6. Loss of miR-638 promotes a mesenchymal-like transition in HCC cells. The overexpression of miR-638 in MHCC-97H cells increased the expression of the epithelial cell marker E-cadherin and decreased the expression of the mesenchymal cell marker N-cadherin and vimentin (A). In contrast, the expression of the antagomiR to miR-638 decreased E-cadherin expression and increased N-cadherin and vimentin expression (B). Immunohistochemical analysis of E-cadherin and vimentin in HCC samples. In cases of high miR-638 expression (a and c); there was strong E-cadherin and no detectable vimentin protein expression in the same tissue section. In contrast, in the case of low miR-638 expression (b and d), there was no detectable E-cadherin and strong vimentin protein expression (C). Values are depicted as mean $\pm \mathrm{SEM} ;{ }^{*} \mathrm{P}<0.05$ by t-test.

However, on the contrary, miR-638 was downregulated in colorectal carcinoma cells and loss of miR-638 in vitro promotes cell invasion and a mesenchymal-like transition by targeting SOX2 expression in CRC cells. Moreover, miR-638 inhibited cell proliferation by targeting phospholipase D1 in human gastric carcinoma (22). In addition, downregulation of miR-638 enhanced invasion and proliferation by regulating SOX2 and induced EMT in NSCLC. miR-638-mediated regulation of BRCA1 affected DNA repair and sensitivity to UV and cisplatin in triple-negative breast cancer (6).

In the present study, we initially confirmed that the mean expression level of miR-638 was significantly downregulated in HCC tissues compared to matched tumor-adjacent tissues, and similar result was obtained in HCC cells. Reduced miR-638 expression conferred a significant correlation with malignant clinicopathological characteristics of HCC patients, including high histological grade, venous infiltration and advanced TNM stage. Moreover, we found that high miR-638 group had a significantly better 5-year OS and DFS in HCC patients. Multivariate Cox repression analysis indicated that miR-638 was an independent prognostic factor for predicting survival of HCC patients. Taken together, these results suggest that miR-638 is critical for prognosis outcome of HCC patients. Mechanistically, gain- and loss-of-function experiment confirmed miR-638 inhibited HCC cell migration and invasion in vitro, which suggested that miR-638 was a tumor suppressor and invasion-related miRNA in HCC. Importantly, we identified SOX2 as a direct target of miR- 638 by luciferase report activity. Our data also showed miR-638 overexpression diminished while miR-638 knockdown promoted SOX2 mRNA and protein expression in HCC cell lines by directly binding the 3'-UTR of SOX2. Similarly, we tried to elucidate the reverse correlation of miR-638 and SOX2 expression in HCC tissues. The effects of miR-638 alteration on migration and invasion of HCC cells were also abolished by SOX2 modulation, which indicated that miR-638 suppressed migration and invasion, at least in part, by targeting SOX2. These data were consistent with previous studies $(8,19)$. Collectively, these results suggested miR-638 may play critical role of a negative regulator or 
A

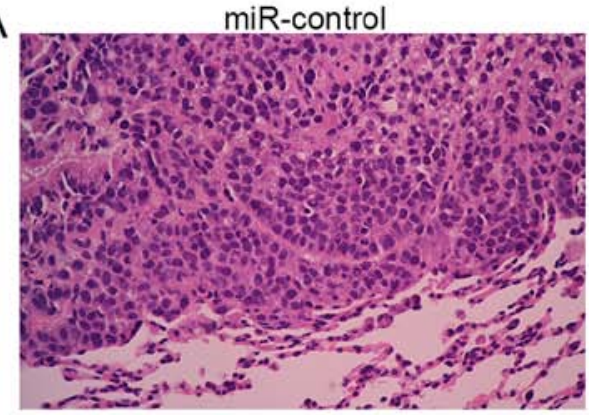

B
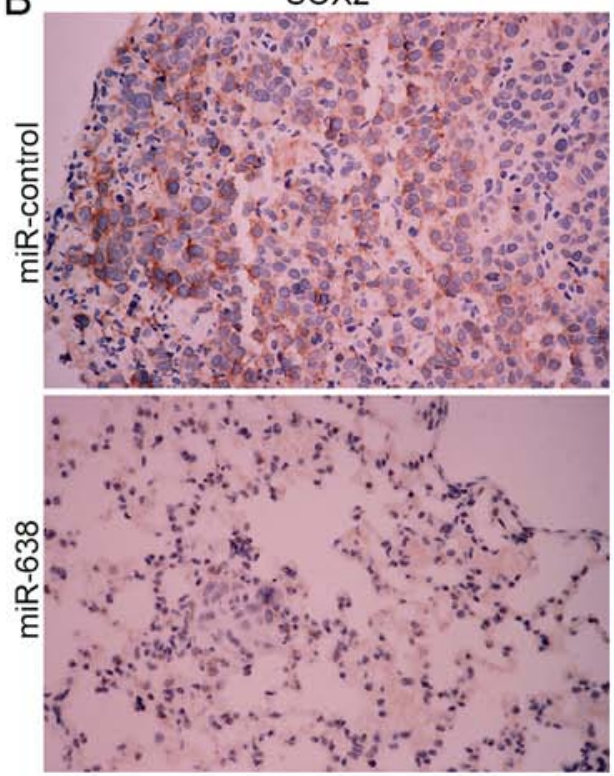

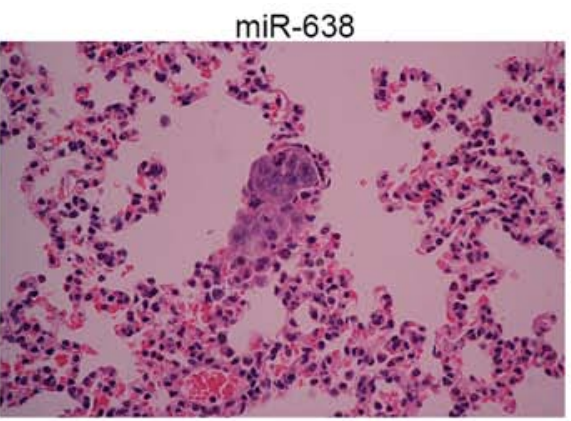

E-cadherin
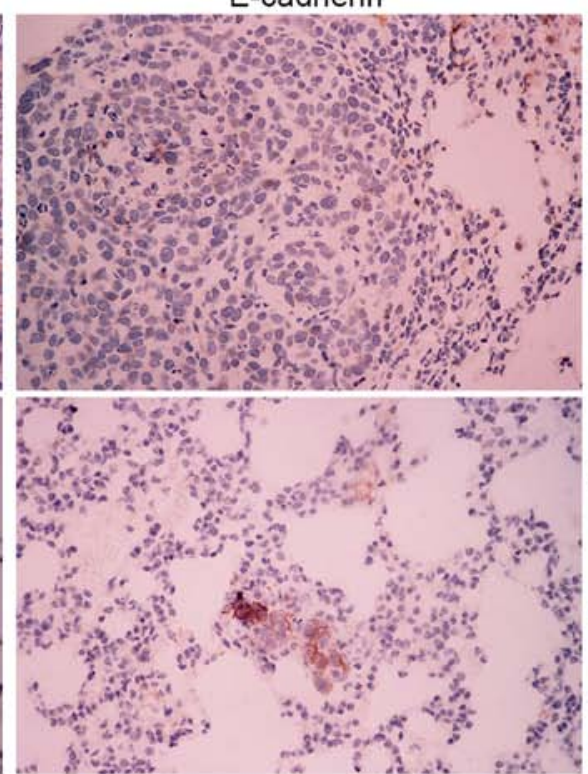
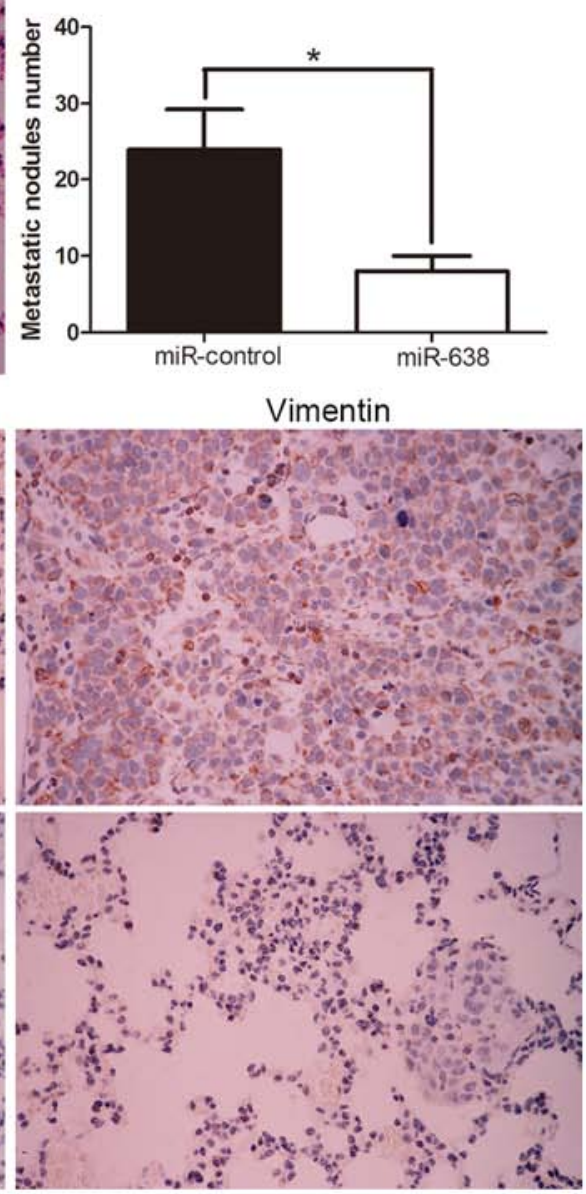

Figure 7. miR-638 mediated repression of SOX2 ameliorates the metastatic potential of HCC cells in vivo. (A) Representative hematoxylin and eosin (H\&E) images of metastatic nodules from the mouse lung tissue sections of the MHCC-97H-miR-control group and the MHCC-97H-miR-638 group. The number of metastatic nodules in the lungs of each group is presented as the mean \pm SD. (B) The representative picture of immunochemical staining of serial lung sections for SOX2, E-cadherin and vimentin staining in the MHCC-97H-miR-control group and the MHCC-97H-miR-638 group. ${ }^{*} \mathrm{P}<0.05$ by $\mathrm{t}$-test.

tumor suppressor for the cell migration and invasion by targeting SOX 2 expression.

Recently, increasing evidence has demonstrated that SOX2 participated in oncogenesis and progression of various cancers by regulation of multiple cell signaling pathways, including HCC (23-28). SOX2 expression predicts poor survival of HCC patients and it promotes liver cancer cell invasion by activating Slug (24). In pancreatic ductal adenocarcinoma cells, SOX2 functions as a molecular rheostat to control the growth, tumorigenicity and drug response (29). Moreover, Li et al demonstrated that SOX2 could promote tumor metastasis by stimulating epithelial-to-mesenchymal transition via regulation of $\mathrm{Wnt} / \beta$-catenin signal pathway (30). Here, we also found that miR-638 inhibited tumor migration and invasion and EMT phenotype through targeting SOX2 in vitro and in vivo. In addition, we found the miR-638 expression was inversely correlated with the EMT marker (E-cadherin and vimentin) expression, which reinforce the biological function of miR-638 on EMT. Moreover, we discovered that the overexpression of miR-638 suppressed the lung metastasis through targeting SOX2, and increased E-cadherin expression and decreased vimentin expression. These data confirmed that the functional effect of miR-638 on HCC in vitro and in vivo was dependent on SOX2.
In summary, we demonstrated that miR-638 was downregulated in HCC tissues and cell lines, and its expression was correlated with malignant clinicopathological features. Furthermore, we confirmed miR-638 inhibited cell migration and invasion in vitro and in vivo by inhibiting SOX2 mediated EMT signaling pathway. These results suggest that miR-638 is a potential invasion-associated tumor suppressor in HCC. In future, therapeutic interventions concentrating on miR-638-SOX2 may help repress the development and metastasis of HCC.

\section{References}

1. Bartel DP: MicroRNAs: Genomics, biogenesis, mechanism, and function. Cell 116: 281-297, 2004.

2. Rosa A and Brivanlou AH: MicroRNAs in early vertebrate development. Cell Cycle 8: 3513-3520, 2009.

3. Vasudevan S, Tong Y and Steitz JA: Switching from repression to activation: microRNAs can up-regulate translation. Science 318: 1931-1934, 2007.

4. Liu Z, Dou C, Yao B, Xu M, Ding L, Wang Y, Jia Y, Li Q, Zhang H, Tu K, et al: Ftx non coding RNA-derived miR-545 promotes cell proliferation by targeting RIG-I in hepatocellular carcinoma. Oncotarget 7: 25350-25365, 2016

5. Tu K, Zheng X, Dou C, Li C, Yang W, Yao Y and Liu Q: MicroRNA-130b promotes cell aggressiveness by inhibiting peroxisome proliferator-activated receptor gamma in human hepatocellular carcinoma. Int J Mol Sci 15: 20486-20499, 2014. 
6. Tan X, Peng J, Fu Y, An S, Rezaei K, Tabbara S, Teal CB, Man YG, Brem RF and Fu SW: miR-638 mediated regulation of BRCA1 affects DNA repair and sensitivity to UV and cisplatin in triple-negative breast cancer. Breast Cancer Res 16: 435, 2014.

7. Wang F, Lou JF, Cao Y, Shi XH, Wang P, Xu J, Xie EF, Xu T, Sun RH, Rao JY, et al: miR-638 is a new biomarker for outcome prediction of non-small cell lung cancer patients receiving chemotherapy. Exp Mol Med 47: e162, 2015.

8. Xia Y, Wu Y, Liu B, Wang P and Chen Y: Downregulation of miR-638 promotes invasion and proliferation by regulating SOX2 and induces EMT in NSCLC. FEBS Lett 588: 2238-2245, 2014.

9. Lin Y, Li D, Liang Q, Liu S, Zuo X, Li L, Sun X, Li W, Guo M and Huang Z: miR-638 regulates differentiation and proliferation in leukemic cells by targeting cyclin-dependent kinase 2 . J Biol Chem 290: 1818-1828, 2015.

10. Sand M, Skrygan M, Sand D, Georgas D, Hahn SA, Gambichler T, Altmeyer P and Bechara FG: Expression of microRNAs in basal cell carcinoma. Br J Dermatol 167: 847-855, 2012.

11. Zhang J, Fei B, Wang Q, Song M, Yin Y, Zhang B, Ni S, Guo W, Bian Z, Quan C, et al: MicroRNA-638 inhibits cell proliferation, invasion and regulates cell cycle by targeting tetraspanin 1 in human colorectal carcinoma. Oncotarget 5: 12083-12096, 2014.

12. Zhao LY, Yao Y, Han J, Yang J, Wang XF, Tong DD, Song TS, Huang $\mathrm{C}$ and Shao Y: miR-638 suppresses cell proliferation in gastric cancer by targeting Sp2. Dig Dis Sci 59: 1743-1753, 2014.

13. Bhattacharya A, Schmitz U, Raatz Y, Schönherr M, Kottek T, Schauer M, Franz S, Saalbach A, Anderegg U, Wolkenhauer O, et al: miR-638 promotes melanoma metastasis and protects melanoma cells from apoptosis and autophagy. Oncotarget 6 : 2966-2980, 2015.

14. Li P, Liu Y, Yi B, Wang G, You X, Zhao X, Summer R, Qin Y and Sun J: MicroRNA-638 is highly expressed in human vascula smooth muscle cells and inhibits PDGF-BB-induced cell proliferation and migration through targeting orphan nuclear receptor NOR1. Cardiovasc Res 99: 185-193, 2013.

15. Cheng J, Chen Y, Zhao P, Liu X, Dong J, Li J, Huang C, Wu R and Lv Y: Downregulation of miRNA-638 promotes angiogenesis and growth of hepatocellular carcinoma by targeting VEGF. Oncotarget 7: 30702-30711, 2016.

16. Kalluri R and Weinberg RA: The basics of epithelial-mesenchymal transition. J Clin Invest 119: 1420-1428, 2009.

17. Spaderna S, Schmalhofer O, Hlubek F, Berx G, Eger A, Merkel S, Jung A, Kirchner T and Brabletz T: A transient, EMT-linked loss of basement membranes indicates metastasis and poor survival in colorectal cancer. Gastroenterology 131: 830-840, 2006

18. Ye J, Wu D, Shen J, Wu P, Ni C, Chen J, Zhao J, Zhang T, Wang X and Huang J: Enrichment of colorectal cancer stem cells through epithelial-mesenchymal transition via CDH1 knockdown. Mol Med Rep 6: 507-512, 2012.
19. Ma K, Pan X, Fan P, He Y, Gu J, Wang W, Zhang T, Li Z and Luo X: Loss of miR-638 in vitro promotes cell invasion and a mesenchymal-like transition by influencing SOX2 expression in colorectal carcinoma cells. Mol Cancer 13: 118, 2014.

20. Bosch FX, Ribes J, Díaz M and Cléries R: Primary liver cancer: Worldwide incidence and trends. Gastroenterology 127 (Suppl 1): S5-S16, 2004

21. El-Serag HB and Rudolph KL: Hepatocellular carcinoma: Epidemiology and molecular carcinogenesis. Gastroenterology 132: 2557-2576, 2007.

22. Zhang J, Bian Z, Zhou J, Song M, Liu Z, Feng Y, Zhe L, Zhang B, Yin Y and Huang Z: MicroRNA-638 inhibits cell proliferation by targeting phospholipase D1 in human gastric carcinoma. Protein Cell 6: 680-688, 2015.

23. Huang P, Qiu J, Li B, Hong J, Lu C, Wang L, Wang J, Hu Y, Jia W and Yuan Y: Role of Sox 2 and Oct4 in predicting survival of hepatocellular carcinoma patients after hepatectomy. Clin Biochem 44: 582-589, 2011

24. Sun C, Sun L, Li Y, Kang X, Zhang S and Liu Y: Sox 2 expression predicts poor survival of hepatocellular carcinoma patients and it promotes liver cancer cell invasion by activating Slug. Med Oncol 30: 503, 2013.

25. Zhao X, Sun B, Sun D, Liu T, Che N, Gu Q, Dong X, Li R, Liu Y and Li J: Slug promotes hepatocellular cancer cell progression by increasing sox 2 and nanog expression. Oncol Rep 33: 149-156, 2015.

26. Wen W, Han T, Chen C, Huang L, Sun W, Wang X, Chen SZ, Xiang DM, Tang L, Cao D, et al: Cyclin G1 expands liver tumorinitiating cells by Sox 2 induction via Akt/mTOR signaling. Mol Cancer Ther 12: 1796-1804, 2013.

27. Zhao C, Li Y, Zhang M, Yang Y and Chang L: miR-126 inhibits cell proliferation and induces cell apoptosis of hepatocellular carcinoma cells partially by targeting Sox 2 . Hum Cell 28: 91-99, 2015.

28. Velpula KK, Dasari VR, Tsung AJ, Dinh DH and Rao JS: Cord blood stem cells revert glioma stem cell EMT by down regulating transcriptional activation of Sox 2 and Twist1. Oncotarget 2: 1028-1042, 2011.

29. Wuebben EL, Wilder PJ, Cox JL, Grunkemeyer JA, Caffrey T, Hollingsworth MA and Rizzino A: SOX2 functions as a molecular rheostat to control the growth, tumorigenicity and drug responses of pancreatic ductal adenocarcinoma cells. Oncotarget 7: 34890-34906, 2016.

30. Li X, Xu Y, Chen Y, Chen S, Jia X, Sun T, Liu Y,Li X, Xiang R and $\mathrm{Li}$ N: SOX2 promotes tumor metastasis by stimulating epithelialto-mesenchymal transition via regulation of $\mathrm{WNT} / \beta$-catenin signal network. Cancer Lett 336: 379-389, 2013. 